\title{
“Bom é ser do Rio”: aspectos sobre a trajetória musical de João Leal Brito na cidade do Rio de Janeiro (1941-1954)
}

\author{
"Bom é ser do Rio": aspectos sobre la trayectoria musical de João Leal \\ Brito en la ciudad de Rio de Janeiro (1941-1954)
}

"Bom é ser do Rio": aspects about the musical trajectory of João Leal Brito in the city of Rio de Janeiro (1941-1954)

\author{
Vinicius Carvalho Veleda ${ }^{1}$ \\ Jonas Moreira Vargas ${ }^{2}$
}

\begin{abstract}
Resumo
O seguinte artigo visa estudar a trajetória do pianista João Leal Brito na cidade do Rio de Janeiro. João começou sua carreira artística em 1935 atuando como pianista na Rádio Cultura, em sua terra natal, Pelotas/RS. Não demorou para ser contratado pela Rádio Farroupilha de Porto Alegre, por onde atuou entre os anos de 19361938. Foi para São Paulo no ano seguinte a fim de atuar em rádios e boates da capital paulista. Até que, por volta de 1941, mudou-se para a então Capital Federal, a cidade do Rio de Janeiro, onde permaneceu até seu falecimento em setembro de 1966. Nesta cidade, primeiramente, João Brito integrou a orquestra do maestro Napoleão Tavares, e em 1944 formou seu próprio conjunto. Nestes meados dos anos de 1940, Britinho foi contratado pelas rádios Globo e Tupi. No início da década de 1950, passou a atuar na complexa noite carioca, mais precisamente entre as boates situadas na Zona Sul, em Copacabana. Entre as boates que atuou estão: Perroquet, Vogue e Casablanca. Contudo, foi nesta última boate, que se tornou famoso pianista, arranjador e maestro. Por lá permaneceu por pelo menos dois anos, atuando em oito espetáculos. Para este artigo, propomos, portanto, estudar a participação de Britinho nestas boates entre 1952-1954.
\end{abstract}

Palavras-Chave: Boates; João Leal Brito; música nos anos 1950; trajetória; Rio de Janeiro.

\section{Resumen}

El siguiente artículo pretende estudiar la trayectoria del pianista João Leal Brito en la ciudad de Río de Janeiro. João comenzó su carrera artística en 1935 actuando como pianista en Radio Cultura, en su tierra natal, Pelotas/RS. No tardó en ser contratado por la Radio Farroupilha de Porto Alegre, por donde actuó entre los años 1936-1938. Fue para São Paulo el año siguiente a fin de actuar en radios y discotecas de la capital paulista. Hasta que, hacia 1941, se mudó a la entonces Capital Federal, la ciudad de Río de Janeiro, donde permaneció hasta su fallecimiento en septiembre de 1966. En esta ciudad, primero, João Brito integró la orquesta del maestro Napoleão Tavares, y en 1944 formó su propio conjunto. En estos mediados de los años 1940, Britinho fue contratado por las radios Globo y Tupi. A principios de la década de 1950, pasó a actuar en la compleja noche carioca, más precisamente entre las discotecas situadas en la "Zona Sul", en Copacabana. Entre las discotecas que actuó están: Perroquet, Vogue y Casablanca. Sin embargo, fue en esta última discoteca, que se hizo famoso pianista, arreglador y maestro. Por allí permaneció por al menos dos años, actuando en ocho espectáculos. Para este artículo, proponemos, por lo tanto, estudiar la participación de Britinho en estas discotecas entre 1952-1954.

\footnotetext{
1 Mestrando em História; Universidade Federal de Pelotas; Pelotas; Rio Grande do Sul; Brasil; veledavinicius@gmail.com. Trabalho apresentado no III Encontro Humanístico Multidisciplinar e II Congresso Latino-Americano em Estudos Humanísticos Multidisciplinares, Jaguarão/RS, Brasil, 2017.

${ }_{2}$ Doutor em História; Universidade Federal de Pelotas; Pelotas; Rio Grande do Sul; Brasil; jonasmvargas@yahoo.com.br. Orientador.
} 
Palabras claves: Boates; João Leal Brito; música en los años 1950; trayectoria; Rio de Janeiro.

\begin{abstract}
The following article intends study the trajectory of the pianist João Leal Brito in the city of Rio de Janeiro. João began his artistic career in 1935 as a pianist at Radio Cultura in his hometown of Pelotas/RS. Soon he was hired by Farroupilha radio station in Porto Alegre, where he worked between 1936 and 1938. He went to São Paulo the following year to work in radios and nightclubs in the city of São Paulo. Then, around 1941, he moved to the then Federal Capital, the city of Rio de Janeiro, where he remained until his death in September 1966. In this city, first, João Brito integrated the orchestra of the band-leader Napoleão Tavares; and in 1944 he formed his own band. In the mid-1940s, Britinho was hired by the Globo and Tupi radio stations. At the beginning of the decade of 1950, it began to act in the complex night Rio, more precisely between the nightclubs located in the "Zona Sul", in Copacabana. Among the clubs he has performed are: Perroquet, Vogue and Casablanca. However, it was in this last nightclub, that became famous pianist, arranger and band-leader. He remained there for at least two years, performing in eight shows. For this article, we propose, therefore, to study the participation of Britinho in these clubs between 1952-1954.
\end{abstract}

Keywords: Nightclubs; João Leal Brito; music in the 1950s; trajectory; Rio de Janeiro

\title{
1. Introdução
}

No ano de 1965, já no final de sua carreira, o pianista, maestro e compositor popular João Brito lançou o samba em parceria com o também compositor Fernando César intitulado: "Bom é ser do Rio". Já na primeira frase da canção podemos ouvir: "terra igual não há ao Rio”, em uma explícita exaltação à cidade do Rio de Janeiro.

João Adelino Leal Brito, tornou-se conhecido apenas como "Britinho", ou ainda "Leal Brito". Ele nasceu no extremo sul do Brasil, mais precisamente na cidade de Pelotas, Rio Grande do Sul, em maio de 1917 e faleceu na cidade do Rio de Janeiro em setembro de 1966.

Britinho adveio de uma família de músicos. Seu pai, João Adelino Campos de Brito; o tio, Henrique Brito e o irmão, Rubens Leal Brito, também se dedicaram a música profissionalmente na cidade de Pelotas. João Campos foi professor particular de piano e também professor na Sociedade Musical União Democrata, entre finais dos anos de 1910 e 1930; Henrique integrou a orquestra da rádio Cultura de Pelotas entre os anos de 1930 e 1940; seu irmão, nascido em 1913, Rubens, também foi reconhecido pianista, sobretudo seus choros e valsas, escritos durante a década de 1940. Rubens iniciou a carreira no mesmo período do irmão, João Adelino, na rádio Cultura de Pelotas em 1935; todavia, já no ano seguinte, Rubens foi contratado pela rádio Gaúcha, de Porto Alegre; por volta de 1939 foi contratado para ser pianista na Rádio Mayrink Veiga, no Rio de Janeiro.

A carreira de João Brito foi curta em sua terra natal. Assim como seu irmão, Rubens, ele mudou-se para Porto Alegre em 1936. Entretanto, João foi integrar o cast da rádio Farroupilha até meados de 1939. Neste mesmo ano mudou-se para a cidade de São Paulo, atuando em diversas rádios e boates. 
Em 1941 transferiu-se para o Rio de Janeiro, sendo contratado primeiramente para atuar como pianista da orquestra do maestro Napoleão Tavares. Formou seu próprio conjunto anos mais tarde, em 1944. Durante os meados dos anos de 1940 trabalhou ainda nas rádios Globo e Tupi e fez arranjos para a rádio Nacional. Na década de 1950 passou a investir na carreira fonográfica; junto a carreira nos discos Britinho seguiu a carreira de "pianista da noite", tornando-se popular músico das boates situadas na Zona Sul do Rio, mais precisamente na praia de Copacabana. Trabalhou em boates como como Perroquet, Vogue e Casablanca, entre outras. Contudo, a boate onde Britinho tornou-se mais conhecido foi o Casablanca, que tinha como proprietário o influente Carlos Machado. Nesta boate, Britinho foi orquestrador e arranjador dos espetáculos realizados entre 1952 e 1956.

Após sair da boate Casablanca, Britinho destinou sua carreira quase que exclusivamente a produção fonográfica, trabalhando apenas de forma esporádica em boates, clubes, festas de formatura, dentre outros eventos. Entre 1951-1965 o músico trabalhou em pelo menos 120 discos por diversas gravadoras. Lançou 66 discos como artista principal, mas também foi, em discos com outros artistas, pianista, arranjador, orquestrador ou maestro. Uma questão importante em sua discografia é o fato dele utilizar diversos pseudônimos em suas gravações, tais como: Pierre Kolmann, Franca Villa, Tito Romero, Miriam Presley, Jone Braith (que por vezes também aparece como John Britt), dentre outras denominações.

O presente trabalho integra a pesquisa de mestrado (2016-2018) intitulada: "A vida é um samba: a trajetória do pianista João Leal Brito - "Britinho" (1917-1966)", realizada para o Programa de pós-graduação em História (PPGH) da Universidade de Pelotas. Contudo, este resumo expandido, abordará somente a trajetória de João Brito na cidade do Rio de Janeiro, entre 1941-1954, ou seja, do período que chegou ao Rio, até o período que se dedicou às noites cariocas, mais precisamente nas boates. A primeira boate no Rio de Janeiro onde Britinho atuou foi o Perroquet; nesta boate além de pianista, liderou a orquestra. Neste mesmo ano, passou ainda pela famosa boate Vogue, situada no Leme, em Copacabana, atuando como pianista. Mas foi na boate Casablanca que Britinho tornou-se conhecido no meio artístico carioca. Nesta boate foi o responsável pela contratação dos músicos do conjunto, além de ser o orquestrador dos espetáculos, também conhecidos na época como "teatro da madrugada", ou ainda "teatro de revista da madrugada". No Casablanca participou dos seguintes espetáculos: "Como é diferente o amor em Portugal" em 1952; "Feitiço da Vila" e "Acontece que sou baiano" (estrelando Dorival Caymmi), ambos em 1953; "Esta vida é um carnaval", "Madame Satã", "Quo Vadis" e "Este Rio moleque", todos em 1954. Este tipo de espetáculo foi desenvolvido por Carlos Machado, conhecido como "El rey de la noche"; neles eram 
aliados o teatro e a música a um contexto literário, que geralmente abordava um tema nacional como o samba, o carnaval, ou ainda alguma personalidade de vulto da música brasileira, como por exemplo Noel Rosa (Feitiço da Vila) e Dorival Caymmi (Acontece que eu sou baiano).

Como metodologia, utilizaremos os estudos que se aproximam da chamada "História nova da música", desenvolvida primeiramente por Arnaldo Daraya Contier (1991) e seguida por autores como Marcos Napolitano (2005) e José Vinci de Moraes (2010). Empregaremos ainda aqueles referenciais teóricos relacionados com o estudo de trajetórias e biografias históricas, entre os autores estão: Pierre Bourdieu (2006), Giovanni Levi (2000 e 2006), François Dosse (2009) e Benito Schmidt (2004). Por fim, utilizamos aqueles trabalhos que estudam uma trajetória ou biografia onde o personagem estudado é um músico - cantor ou instrumentista. São obras como: Alcir Lenharo (1995), Márcia Ramos de Oliveira (1995), Maria Izilda Matos (2005) e Sérgio Estephan (2011).

Para estudar a trajetória de Britinho utilizaremos como fontes: os discos lançados pelo pianista entre os anos de 1951-1966 (120 discos); as músicas de sua autoria (72); as matérias de jornais que o citam, sobretudo aquelas oriundas da imprensa periódica nas cidades de Pelotas, Porto Alegre, São Paulo e Rio de Janeiro; e ainda as fotografias, anúncios de boates e anúncios de rádio.

\title{
2. Desenvolvimento
}

\subsection{As boates do bairro de Copacabana}

\begin{abstract}
"Boite"... teoricamente é o lugar onde o grã-fino se diverte, praticamente é um botequim de luzes apagadas, medicinalmente é um excelente local para intoxicações, quer estomacais, quer intestinais, comercialmente é um grande negócio e geograficamente é uma pista de dança cercada de mesas por todos os lados... se dividem - tal como as costelas - em fixas, falsas e flutuantes. Fixas são aquelas ligadas a hotéis e, por isso mesmo, tanto faz dar lucro como prejuízo que está sempre funcionando... As flutuantes são aquelas que abrem na raça e depois o proprietário vê que o rebolado é diferente e então fecha... Finalmente as falsas são aquelas abertas com o rótulo de "boites", não passam de espeluncas ${ }^{3}$.
\end{abstract}

O termo "boîte de nuit" surgiu na França em meados dos anos de 1930. A palavra "boîte" significa "caixa" e "nuit" significa "noite". "Boîte de nuit" constituía então em uma casa noturna com o interior à meia-luz, destinada para jantar, conversar e/ou dançar. Para Ruy Castro, o interior dessas casas dava-se a sensação de ser sempre noite, pois não possuíam

\footnotetext{
${ }^{3}$ PRETA, Stanislaw Ponte. Reportagem de bolso. Última Hora, Rio de Janeiro, 21 maio 1956, apud, MESQUITA, 2008, p.115.
} 
janelas voltadas para o exterior. Os horários de funcionamento começavam a partir das sete da noite, indo madrugada adentro, até o início da manhã. Era ainda aonde os casais tinham liberdade para namorar, conversar em sussurros, dançar de rosto colados e ficarem levemente embriagados. A música ambiente era geralmente comandada por um pianista ou saxofonista; mas junto a eles, também haviam cantores e cantoras que interpretavam canções românticas. As mulheres só podiam ir acompanhadas por um homem. A vestimenta para os homens era o terno e gravata e as mulheres o vestido de grife famosas. Cobrava-se uma consumação mínima para entrada, além do couvert artístico. O termo "boîte de nuit" foi simplificado somente a "boîte" em meados dos anos de 1940, diferenciando-se das expressões já conhecidas: night-club, cabaré, bistrô, café, piano-bar, supper-club, entre outros (CASTRO, 2015 , p.33).

Podemos considerar que as primeiras boates em Copacabana surgiram por iniciativa do empresário e fundador do hotel Copacabana Palace, Octavio Guinle. Sua ideia era aproveitar os amplos salões vazios no interior do hotel para realização de shows. Para isso, criou em 1938 o Golden Room, um local suntuoso com capacidade para 400 pessoas, palco para grande orquestra, pista de dança e bar. Era visitado pelos ricos e artistas estrangeiros que se instalavam no hotel. Nos primeiros anos Octávio nomeou seu sobrinho Carlos Guinle para ser o diretor artístico do Golden Room, todavia, em 1943, efetivou o austríaco Max Stuckart para a função. As atrações mais frequentes eram apresentadas pelos crooners ${ }^{4}$ que cantavam, com a luz baixa, em diversos gêneros e idiomas, mas principalmente em francês, espanhol ou inglês eram utilizados. Entretanto, o Copacabana Palace possuía ainda outros salões a serem ocupados. E por influência de Max Stuckart, Octávio Guinle criou o Meia Noite, ainda em 1943. Este apresentava um salão menor e mais aconchegante que o Golden Room, e era mais proposto a música; possuía mesas espelhadas e iluminação à luz de velas. A trilha sonora da casa eram canções românticas e sentimentais, mas existiam também apresentações com músicos de jazz, levados por Carlinhos Guinle. Como as boates estavam a poucos metros uma da outra, era hábito que músicos e crooners transitassem de uma boate para a outra durante a noite (CASTRO, 2015, p.34).

O Vogue surgiu quando o empresário Conde de Atalaia construiu um novo hotel na cidade situado na Avenida Princesa Isabel, entre o Leme e Copacabana. Era um hotel de luxo, com 12 andares, mais de 30 apartamentos, boate, restaurante, espaço para reuniões de

\footnotetext{
${ }^{4}$ Crooner: no Brasil crooner era um cantor ou cantora que difundia canções populares. Ele geralmente era acompanhado por uma orquestra ou conjunto. O termo ainda pode designar o cantor que canta em mais de um estilo; ou canta músicas que estão nas paradas de sucesso. Em inglês, crooner pode ser utilizado somente para o cantor masculino.
} 
negócios, exposições e todos os serviços de primeira linha. Em pouco tempo, o Conde passou a administração dos negócios do Hotel Vogue para Maximiliam von Stuckart (chamado de "Barão de Stuckart"), ex boate Night and Day. Assim como na boate anterior, criou uma cozinha de cinco estrelas para a boate e o restaurante. O Vogue tornou-se ponto gastronômico do Rio. O espaço destinado a boate Vogue possuía duas pistas de dança, com uma pequena orquestra tocando em cada uma. Uma das maiores atrações da boate foi sem dúvida o pianista austríaco Salomon Rubin, mais conhecido apenas como Sacha. Logo, tornou-se símbolo do Vogue na noite carioca. O Vogue tornou-se um local privilegiado onde corriam rapidamente muitas informações políticas, da imprensa, operações cambiais, entre outras questões. Reuniam-se na boate grandes comerciantes, banqueiros, diplomatas, ministros, políticos, empresários, grã-finos, proprietários de jornais, colunistas, artistas e boêmios.

Com o sucesso do Vogue, aconteceu que ampliou o número de boates em Copacabana. Em 1948 foi inauguradas: Chez Aimée, na Avenida Atlântica, com teatro para 150 pessoas; Chez Penny, do pianista Claude Austin, localizado na rua Carvalho de Mendonça, onde anos mais tarde chamou-se de "Beco das Garrafas". Contudo, Austin e seu conjunto foram contratados pelo Vogue, isso levou-o a vender sua boate. Logo, o Chez Penny foi transformado em um restaurante oriental, Mei-Ling. Inaugurou neste ano também a boate Pigalle, e a estrela principal da casa era o pianista Bené Nunes, já conhecido em todo o circuito cultural do Rio de Janeiro, entre circos, gafieiras e cassinos. Ano seguinte surgiram boates como o Tasca, localizado de frente para o Vogue, no outro lado da rua da Avenida Princesa Isabel; Acapulco, que trazia unicamente atrações mexicanas e cubanas. No outro extremo da praia de Copacabana, no posto 6, abriu o Rosie Marie, no térreo do Cassino Atlântico; durou pouco mais de um ano e depois foi transformado na boate Embassy (CASTRO, 2015, p.57).

Em princípios da década de 1950 aumentou-se vertiginosamente a quantidade de boates em Copacabana. Dentro do Hotel Excelsior, abriu a boate Stadium; no Leme fechou o Chez Aiméé onde logo abriu o Flair. Perto do Forte de Copacabana, no posto 6, abriu a casa Ranchinho do Alvarenga, que tornou-se popular por suas música ao vivo. Mas a grande novidade em 1950 foi o Club 36, na rua Rodolfo Dantas. Uma boate subterrânea que cabia no máximo 40 pessoas. A primeira atração por oito meses consecutivos foi o compositor e cantor baiano Dorival Caymmi. O processo de profusão das boates em Copacabana sucedeu de maneira intensa. Em curto período, já era perceptível a popularização das boates. Haviam as boates de grã-finos como Golden Room, Meia-Noite e Vogue (e posteriormente o Casablanca e Sacha's também), contudo, perto dali, na Avenida Prado Júnior, começavam a surgir em 
início dos anos de 1950, uma série de casas noturnas mais "democráticas”, que tentavam conservar exterioridade como boate. Elas passaram a ser chamadas de "inferninhos" (CASTRO, 2015, p.58).

Entre as boates mais tradicionais do Rio de Janeiro está, sem dúvidas, o Sacha's "seven to seven" - inaugurado no final do ano de 1954 (SANTOS, 1996, p.41-8). Essa boate surgiu devido aos interesses de Carlos Machado, "O rei da noite" carioca. Machado ofereceu uma sociedade ao pianista Sacha Rubin (que em 1954 pertencia ao Vogue), em abrir uma boate onde ele seria a atração principal diariamente; além da boate levar o seu nome "Sacha's". A ideia de Machado era justamente criar uma casa que desafiasse o Vogue, uma das maiores boates do Brasil na ocasião. E não demorou para os frequentadores do Vogue o trocarem pelo Sacha's. Mas o golpe mais duro ao Vogue, não foi a inauguração do Sacha's; foi, sem dúvida o incêndio que dizimou a boate em 1955. Depois do restaurante Vogue, os restaurantes mais frequentados pela boemia neste período foram: Fiorentina, Cabeça Chata, Chez Ruffin e a Cantina do Sorento. E próximo ao Forte de Copacabana: Ranchinho do posto 6, Posto 5, Tudo Azul, Farolito, o restaurante Cremaillère e Marimbás.

\subsection{Boêmios, intelectuais e artistas migram rumo a Zona Sul}

Durante o Estado Novo (1937-1945) o governo aumentou a vigilância sobre toda a produção cultural do país. Processo que principiou em início dos anos de 1930, após o golpe liderado por Getúlio Vargas e com apoio dos militares. Foi um período marcado especialmente por grande turbulência social. Além do mais, em 1939, o governo federal divulgou a criação do DIP (Departamento de Imprensa e Propaganda), que propunha impor-se com rigor contra aqueles que estivessem ao contrário da ideologia trabalhista divulgada pelo Estado Novo, perseguindo "malandros" e "vadios" ou ainda aqueles que cultuavam o "não trabalho".

O prefeito do Rio do Janeiro Henrique Dosdworth (1937-1945) durante sua administração, realizou profundas mudanças na cidade. Fez inúmeras intervenções na região da Lapa; reformas na Avenida Presidente Vargas (colocando abaixo aproximadamente 500 edifícios) e construiu a Avenida Brasil; pôs fim a Praça Onze; e criou inúmeros parques na cidade. Dosdworth decretou ainda o fechamento maciço dos prostíbulos em 1942; desapropriação de duzentos prédios na Lapa em 1945. E sob mandato do presidente Eurico Gaspar Dutra foram proibidos dos jogos de azar em 1946. Após período de forte repressão e vigilância, o famoso e boêmio bairro da Lapa entrou em declínio e foi esvaziando-se. Devido 
a forte presença policial e a atmosfera repressiva, os intelectuais, boêmios e a clientela chique da Zona Sul afastaram-se do bairro (LENHARO, 1995, p.17-20).

Outro grande revés aos frequentadores da noite nesse período foi o decreto-lei número 9.215, que proibia os jogos de azar em todo o território nacional. Ele pronunciava o fechamento dos cassinos em 30 de abril de 1946.

É provável que o jogo nos cassinos movesse cerca de 300 milhões de dólares por ano no país em 1946. Aproximadamente 70\% deste lucro ficava nos cassinos do Rio de Janeiro; para dar conta da clientela, isso obrigava esses cassinos a empregar em torno de 40 mil funcionários (CASTRO, 2015, p.23). E para o historiador Vicente Santos (2013, p.93) os fechamentos dos estabelecimentos da Lapa e dos cassinos, gradativamente a noite carioca foi se restaurando. Um dos primeiros lugares frequentados, mesmo que timidamente, por artistas, intelectuais, boêmios e políticos como ponto de encontro na Zona Sul foi o Café Central, fundado pelo Português Thomé dos Santos Lamas, em 1874, na rua do Catete 195, no Largo do Machado. Local onde outras gerações boêmias já encontravam-se anteriores. Entre os frequentadores ilustres estão: os literatos Machado de Assis e Manuel Bandeira, os cronistas Rubem Braga e Jota Efege, o pintor Di Cavalcanti e o político Getúlio Vargas. As pequenas boates de Copacabana como: a Tasca, o Mandarim, o Farolito, o Beach Club, o Night and Day logo também passaram a ser frequentadas pelos boêmios e intelectuais (LENHARO, 1995, p.47). Neste período, em meados de 1946, o bairro já possuía localidades importantes para a sociabilidade noturna; as boates eram estes pontos procurados, principalmente pelo glamour. Migrando do Centro para a Zona Sul os boêmios: "mudavam de pouso e de clima, a penumbra das boates substituindo as luzes dos cabarés, do Centro da cidade, e se tornando, uma boemia mais íntima e refinada, regulada a uísque escocês e embalada por nossa música romântica” (MÁXIMO \& DIDIER, 1990, p.483). Sobre a ida da boemia da região central para Copacabana, Joaquim Santos (2013, p.44), comenta:

A ralé de camisa listrada ficou aonde estava. Quem tinha dinheiro e queria se divertir à noite migrou para Copacabana, com seus hotéis luxuosos, boates em penumbra, uísque escocês, uma música chorosa, romântica e com couvert, mas principalmente sem batuque. Não era só uma mudança geográfica. Ficava para trás uma cidade quase que primitiva. Parecia um estilo de vida charmoso, cosmopolita, os passos iniciais na direção de uma exuberância comportamental.

O dia-a-dia notívago de Copacabana acontecia dentro dos bares, restaurantes e boates. Maria Izilda Matos comenta sobre as boates: “no Sorrento e no Maxim's os artistas do rádio e do teatro davam o tom; pela primeira vez, elegiam um ponto de encontro na Zona Sul" 
(MATOS, 2005, p.44). Entretanto, as boates de Copacabana eram um ambiente boêmio distinto da Lapa e do Estácio. Boates como Vogue eram frequentados pela alta sociedade e intelectualidade; o high society, os cronistas da imprensa, a turma da música popular, paulistas ricos em férias (LENHARO, 1995, p.22). Os restaurantes que habituaram-se a ir foram: Furna da Onça, Alpino, Bambu, Tasca, Taberna, OK, Bife de Ouro, Maxim’s, Alvelar, Bolero, Cairo, Alcazar, Marrocos. E os restaurantes franceses, que eram considerados chiques: Bistrô, Cloche d'Or, French Can-Can, Cremaillère e Tout-em-bleu.

\subsection{A ida de Britinho para a cidade do Rio de Janeiro em 1941}

[...] Natural de Pelotas, Rio Grande do Sul, Britinho, cujo nome completo é João Adelino Leal Britto, estudou com seus próprios tios, que eram músicos também. Naquela cidade gaúcha, fez parte do elenco das emissoras locais, Rádios Pelotense e Cultura, tendo depois, em 1938, se transferido para Porto Alegre, onde trabalhou na Rádio Farroupilha. No ano seguinte, mudou-se para São Paulo e lá atuou na Boite Tabú até que, em 1941, foi contratado para o Bar Bolero, no Rio de Janeiro. Mas São Paulo voltou a ser o seu destino e as "boites" Arpège, Oásis e Esplanada o mantiveram sob compromisso até 1944. Nesta Ocasião, Britinho já trabalhava com um conjunto seu e foi com ele que veio fixar-se definitivamente no Rio, contratado pelo Copacabana Palace 5 .

(Britinho) estudou com seus tios no Conservatório de Música. Três anos mais tarde, organizou sua própria orquestra, a melhor que Pelotas havia conhecido por volta de 1936. Irmão do igualmente excelente pianista Rubens Leal Brito (Brito), foi por este chamado para Porto Alegre onde substituiu na Rádio Farroupilha, o então famoso pianista Paulo Coelho. Em 1939, dirigiu-se para São Paulo havendo atuado em diversas estações de rádios e buates. Foi contratado da orquestra de Mário Silva, atuando no Cassino Porchat, em Santos. Em 1941, mudou-se para o Rio de Janeiro, começando a trabalhar na Orquestra de Napoleão Tavares. Ingressou na Rádio Club do Brasil onde foi contratado novamente por Napoleão a Buate Perroquet $[. . .]^{6}$.

A trajetória artística de João Leal Brito "Britinho" iniciou por volta de 1936 ainda em sua terra natal, Pelotas/ RS, atuando principalmente nas rádios Cultura e Pelotense. Neste primeiro período, Britinho tocou com seu irmão, também pianista, Rubens Leal Brito e chegaram a ser conhecidos pelas performances em duo pianístico como "irmãos Brito". Não encontramos informações sobre a presença de Britinho no Conservatório de Pelotas, o que poderia ter ocorrido entre os anos de 1925-1935. É provável que Britinho tenha estudado na Banda Sociedade União Democrata, neste mesmo período e por influência de seu pai e tios. Outra informação extraída destas fontes que não conseguimos averiguar com certeza é sobre a orquestra que ele haveria formado ainda em Pelotas em 1936. Sabemos é que ambos sofreram

\footnotetext{
${ }^{5}$ Britinho e seu piano. Pensando em ti-Britinho em solos de piano. Rio de Janeiro: Sinter, 1957. 1 LP (32 min.) 33rpm, sulco, mono, SLP 1702. (Contracapa).

${ }^{6}$ Britinho e seu Conjunto. Sucessos de Dorival Caymmi. Rio de Janeiro: Continental, 1956. 1 LP (30 min.) 33rpm, sulco, mono, LPP 34. (Contracapa).
} 
influência da família - pai e tios - para o aprendizado de violino e piano e a possível escolha da carreira como músicos. Britinho foi à cidade de Porto Alegre em 1938 por influência de seu irmão Rubens Leal Brito, para substituir o famoso pianista Paulo Coelho na Rádio Farroupilha. Depois de Porto Alegre seu destino foi a cidade de São Paulo, no ano seguinte, atuando principalmente em boates como: Tabú, Oásis e Esplanada. Neste mesmo período foi contratado para ser instrumentista na orquestra de Mário Silva, atuando no Cassino da Ilha Porchat em Santos. Antes de fixar-se definitivamente na cidade do Rio de Janeiro, é possível que Britinho tenha cumprido contrato em boates paulistas

Britinho chegou no Rio de Janeiro somente em 1941 para trabalhar na orquestra do trompetista, maestro e arranjador Napoleão Tavares. Sabemos ainda que seu irmão Rubens Brito também fez carreira como músico no Rio de Janeiro, porém alguns anos antes. É possível que ele Rubens tenha chegado no Rio em 1939 trabalhando como pianista e maestro da rádio Mayrink Veiga. A partir deste ano, encontramos seu nome na programação da rádio, e algumas vezes ele é mencionado como "Britinho da Mayrink Veiga". No cast desta emissora haviam nesta época nomes como o clarinetista e saxofonista Luiz Americano, o pianista argentino Muraro, o flautista Pixinguinha e os cantores: Odete Amaral, Dorival Caymmi, Sílvio Caldas, entre muitos outros ${ }^{7}$. Em junho de 1940, podia-se ler no jornal $O$ Imparcial um comentário sobre o pianista Rubens:

Britinho! Sim, Britinho, apenas! Um nome pequenino como seu dono, que é um pedacinho de gente! Mas um grande pianista.

Tendo feito um curso brilhante no Conservatório de Porto Alegre, Britinho não ficou, porém pedantemente, preso aos clássicos e românticos estrangeiros. Dedicouse à nossa boa música popular e começou a executar e a compor números muito bonitos. Tentado pela metrópole, veio para o Rio e desde o ano passado integra o “cast” da Rádio Mayrink Veiga, onde é cartaz de valor".

Como vimos, seu irmão Rubens também foi conhecido no Rio de Janeiro como "Britinho". Esta é a única fonte que possuímos contendo um resumo biográfico sobre este pianista. Não conseguimos averiguar se há registros sobre sua passagem no Conservatório de Porto Alegre. Suas músicas mais conhecidas no Rio foram: "Romance de uma valsa", "Evocação", "Modulando", entre outros. Suas composições foram geralmente tangos e choros. Assim como na ida de João Brito para Porto Alegre, Rubens, provavelmente, ajudou

\footnotetext{
${ }^{7}$ REVISTA PRA-Nove, Rio de Janeiro, out. 1939.

${ }^{8}$ RÁDIO Novidades. O Imparcial, Rio de Janeiro, 16 jun. 1940.

${ }^{9}$ Até o mês de fevereiro de 2017 achávamos que o "Britinho da Mayrink Veiga" era o João Adelino Leal Brito; e não Rubens Leal Brito. Em nenhuma matéria que possuímos cita qual é o seu primeiro nome. Contudo, a partir de novas fontes, conseguimos distingui-los com maior precisão.
} 
o irmão neste período. Os dois chegaram, do início de 1940 até 1944, a serem reconhecidos como "Britinho" na cidade do Rio de Janeiro.

Como já aludimos, a maior parte da carreira artística de João Leal Brito desenrolou-se na então Capital Federal, a cidade do Rio de Janeiro entre 1941-1966. Entre os locais que atuou nesta cidade estão: os cassinos e as boates (também chamados de "boites", "nightclubs" e "inferninhos"). De forma geral, entre meados dos anos de 1940 até 1960 - estes estabelecimentos eram frequentados pelas elites do Rio e também por pessoas vindas de outros centros importantes do país e do mundo. Para compreendermos este espaço de sociabilidade noturna torna-se imprescindível analisar aonde estavam concentradas as boates e os cassinos: na Zona Sul do Rio de Janeiro. Haviam, então, grandes cassinos no bairro de Copacabana, onde também localizavam-se as boates, distribuídas principalmente entre as regiões do Leme até o Posto 6.

\subsection{A participação de Britinho em boates}

A primeira boate do Rio de Janeiro que possuímos indícios aonde Britinho atuou entre as atrações principais foi a Perroquet, situada no Posto 6 de Copacabana. Provavelmente ele foi contratado por este estabelecimento no início de 1952, juntamente com o também pianista Djalma Ferreira e a crooner Helena de Lima. Britinho e Djalma eram também líderes de banda e cada um chefiava uma pequena orquestra que se revezava para acompanhar Helena de Lima durante o itinerário. Abaixo podemos ver uma matéria sobre a inauguração da boate:

\footnotetext{
Dentro de poucos dias será inaugurada, em Copacabana, a mais elegante "boite" do Rio de Janeiro. Trata-se da "Perroquet", situada na Galeria Alaska, no Posto 6, possuidora de uma decoração inédita e suntuosa. Uma floresta cheia de araras e papagaios, parecendo mesmo, um dos famosos quadros do notável Walt Disney, criação do cenógrafo Souza Mendes.

"Perroquet" será uma "boite" diferente das outras tendo sempre números variados para seus frequentadores, inclusive no chá que será realizado todos os dias das 17 às 19 horas. Lá estarão as orquestras de Djalma Ferreira e Britinho, com a "ladycrooner" Helena de Lima. Coelho, antigo mestre do Cassino da Urca orientará, com sua técnica e trabalho profícuo garçons daquela casa de espetáculos cuja direção geral está entregue a competência de Jaime Redondo que reeditará em Copacabana todos aqueles sucessos apresentados nos áureos tempos do Cassino Icaraí ${ }^{10}$.
}

Como vimos na citação, a imprensa do período no início dos anos 1950 referia-se a boate pelo seu nome francês, "boite", com aspas. Mas também podemos encontrar sem aspas, ou de forma mais aportuguesada - boate. Podem ainda aparecer termos como "casa noturna", "estabelecimento noturno" ou "casa de espetáculo". Era comum que as boates adotassem

\footnotetext{
${ }^{10}$ A NOITE, Rio de Janeiro, 18 de mar. 1952.
} 
nomes franceses como "Perroquet", que pode ser traduzido como papagaio. A coluna menciona, inclusive, que a decoração foi ornamentada por um papagaio que lembrava o personagem Zé Carioca de Walt Disney. A boate ficava na parte interna da Galeria Alaska ${ }^{11}$ inaugurada em 1951. Ela foi a primeira galeria de Copacabana e tinha o desígnio de ser um local destinado a lojas para a alta sociedade; inspirada nas galerias francesas do século XIX, com corredores amplos entre lojas enfileiradas de um lado e de outro. A boate Perroquet situava-se dentro da galeria juntamente com dois cinemas: Royal e Alaska, e acima destes, um condomínio residencial de classe média. Mas o que chama atenção é o local da galeria, na altura do Posto 6, na praia de Copacabana. Com quase 100 metros de extensão, a galeria liga as duas principais avenidas do bairro: a Avenida Nossa Senhora de Copacabana com a Avenida Atlântica. A boate Perroquet e os cinemas foram os primeiros espaços de sociabilidade e diversão da Galeria Alaska. Por volta de 1958 a mídia impressa começou a referir-se que local passava por um processo de marginalização (CARDOSO \& MACHADO, 2015).

O diretor geral da casa, o paulista Jaime Redondo, antes de dedicar-se a produção ou direção artística no Cassino da Urca, Icaraí e Quitandinha (localizado em Petrópolis) foi cantor, compositor e pianista. Djalma Ferreira em 1952 já era reconhecido pianista. Em 1940 atuou em cassinos como: Urca, Quitandinha e também em Poços de Caldas, Minas Gerais. Em 1945 formou o grupo que tornar-se-ia muito popular nas noites e também nas paradas de sucesso das rádios do Rio de Janeiro: Milionários do Ritmo. Seu estilo de compor e interpretar no piano músicas para dançar logo ganhou seguidores - como Britinho, Waldir Calmon e Fat's Elpídio, entre outros. Seu primeiro LP "Parada de dança número 1", lançado em 1953 pela gravadora Musicdisc, teve grande repercussão entre o público. A cantora carioca Helena de Lima foi descoberta pelo radialista César Ladeira no início de 1940 em um programa de calouros. Começou como crooner em 1948 trabalhando na boate Pigalle e depois no Copacabana Palace, no Rio. Em São Paulo fez temporada na boate Oásis. Quando voltou de São Paulo para o Rio, passou a atuar juntamente com Djalma Ferreira no Milionários do Ritmo.

Ao que parece, ainda não estava definido no Perroquet em março de 1952, quem seriam as atrações principais da casa. A cantora Helena de Lima cantava durante os chás dançantes realizados a tarde acompanhada pelo grupo de Britinho ou Djalma Ferreira, e pelo

\footnotetext{
${ }^{11}$ Nos anos de 1970 o local ganhou o apelido de "A galeria do amor" e funcionou como um espaço de sociabilidade homoafetiva no Rio de Janeiro. Atualmente a galeria tem o nome de Galeria Atlântica, mas o prédio continua chamado de Alaska.
} 
turno da noite, no jantar dançante, cantava antes e depois da atração principal com o mesmo acompanhamento. A seguir apresentamos uma matéria sobre a inauguração da boate, que aconteceu dia 8 de abril de 1952:

\begin{abstract}
Recebemos no dia 8 do corrente (mês) a seguinte nota: "será inaugurado hoje finalmente com uma "avant premier" em grande gala, a nova e elegantíssima boite "Perroquet". A aparição da nova casa de diversões noturnas, marca, sem dúvida, um verdadeiro tento no roldão dos acontecimentos sociais da Capital Federal. Inteiramente nova, com uma decoração nunca feita antes no gênero no mundo, "Perroquet" representa, não só para a vida turística do Rio de Janeiro um motivo de atração como um "affaire" de curiosidade para quantos aqui dela passam a desfrutar. O seu primeiro programa artístico, conta com Jean Deny e Dina Greyta, autênticos expoentes da canção francesa, Djalma Ferreira e os milionários do ritmo e ainda Britinho e seu piano mágico, figurando a intérprete, a estrela do nosso rádio e boite Helena de Lima ${ }^{12}$.
\end{abstract}

De acordo com o comentário acima, a imprensa viu com bons olhos a inauguração da boate, colocando-a entre os grandes acontecimentos sociais da Capital Federal. Não encontramos nenhuma referência sobre os cantores franceses atração da boate, Dina Greyta e Jean Deny. Provavelmente a Perroquet não emplacou e com isso fechou precocemente. O que pode ter agravado a situação foi o falecimento do produtor artístico Jaime Redondo em dezembro de 1952. As últimas informações que possuímos sobre Britinho nesta boate foi em 24 de abril de 1952, ainda com o mesmo show dos franceses ${ }^{13}$.

Entre as fontes periódicas utilizadas, possuímos uma que cita João Leal Brito atuando na boate Vogue no dia 21 de março de 1952, ou seja, o pianista tocou em duas boates no mesmo período, o que era comum para a época, considerando que poucas delas mantinham seus instrumentistas sob contrato exclusivo. Isso acontecia com mais frequência entre os crooners e a estrela principal de cada casa de espetáculos, que eram mantidos por mais tempo. Esta extensa matéria escrita pelo cronista e compositor Fernando Lobo, traz ainda rica descrição acerca da programação da noite carioca. Entre as boites citadas estão: Ranchinho do Alvarenga, Maxim's, Monte Carlo, Night and Day, El Relicário, Copacabana Palace, Babalu, Ranchinho (do Alvarenga). Sobre as boates que Britinho participou fez os comentários: "Le Perroquet quase inaugurado" e em seguida, "sem esquecer de Britinho e Sacha, dupla forte no teclado do Vogue ${ }^{14,}$. No final de agosto do mesmo ano Britinho foi apontado novamente: "No Vogue, Sascana e Britinho ao piano e Louis Cole como crooner".

\footnotetext{
${ }^{12}$ LEORNE, Hélio. Pela noite adentro. Diário da Noite, Rio de Janeiro, 10 abr. 1952.

${ }^{13}$ A VIDA começa a meia noite. A Scena Muda, Rio de Janeiro, 21 abr. 1952.

${ }^{14}$ LOBO, Fernando. Depois da 1/2 Noite. A Noite, Rio de Janeiro, 21 mar. 1952.
} 
Este primeiro semestre de 1952 da trajetória de Britinho ainda está longe de ser compreendido mais detalhadamente devido à escassez de fontes, principalmente aquelas oriundas dos jornais do Rio de Janeiro. Só possuímos informações do pianista na boate Perroquet durante os dias que precedem a inauguração até 21 de abril de 1952. Além disto, as informações contidas nas matérias analisadas deste período do Perroquet são repetitivas entre si. Sobre o Vogue a questão é ainda mais delicada. São apenas duas citações que estão separadas por um intervalo de cinco meses, não havendo uma periodicidade regular. Apenas dois dias depois da última matéria no Vogue, João Brito foi anunciado como novo contratado da boate Casablanca. Passamos agora para o período mais documentado de sua trajetória.

\subsection{A boate Casablanca e o teatro da madrugada}

A boate Casablanca surgiu em 1946 por iniciativa do empresário José Caetano de Lima. Inicialmente, o que mais chamou a atenção da nova boate carioca foi sua localização: na Praça General Tibúrcio, na Praia Vermelha, aos pés do já então famoso Pão de Açúcar. A ideia inicial de seu dono era fazer o local como um balneário durante o dia e uma boate durante à noite. Abriria no horário do almoço, seguido de coquetéis até o horário do jantar e mais coquetéis até o horário do grande show. Sendo assim, o Casablanca funcionava durante longas horas por dia e José Lima mantinha três turmas de trabalho: cantores, orquestras, cozinheiros e faxineiros, entre muitos outros funcionários. Menos de um ano após sua inauguração a principal atração da boate contava com a cantora Marlene, acompanhada do pianista Bené Nunes, do clarinetista Abel Ferreira, do violonista Zé Menezes, Chuca-Chuca ao vibrafone, Vidal no contrabaixo e Carequinha na bateria (CASTRO, 2015, p.34-9). Mesmo oferecendo grandes espetáculos, mesas à beira mar e local paradisíaco, o Casablanca não deslanchou. O que obrigou José Caetano a transformá-la em uma churrascaria no início de 1950. Para piorar, o empresário contraiu uma dívida com a boate ficando insustentável o pagamento.

O ressurgimento do Casablanca como boate deve-se a Carlos Machado, que a adquiriu de José Caetano. Neste período Machado já era o grande chefe da boate Monte Carlo, mas o Casablanca possuía mais espaços em suas acomodações. José Carlos Penafiel Machado nasceu na cidade de Porto Alegre, Rio Grande do Sul, em 1908, originário de uma família gaúcha abastada, estancieiros criadores de cavalos. Em sua autobiografia, Carlos Machado (MACHADO \& PINHO, 1978, p.7-8) intitula-se como: 
[...] infantil do Grêmio, campeão de remo, natação e bilhar, dançarino de tango, "coronel" e gigolô, ou melhor, amant du coeur, jornalista, revolucionário bailarino, maestro, dono de restaurantes e boates, produtor e diretor de espetáculos, trabalhei com Maurice Chevalier, fui partenaire de Mistinguette, torcedor do Botafogo, capa do Life, tive muito dinheiro e algumas vezes passei a média com pão e manteiga, criei um estilo de ver a noite, entendo-a e entendo mais ainda os amigos que tive e os inimigos que perdi. Por tudo isso, Sérgio Porto passou a me chamar de "El Rey de la Noche".

Entre as cidades de Porto Alegre e o Rio de Janeiro, Carlos Machado também foi conhecido como "Machadinho de Porto Alegre", "Machadô de la mist" e "O Rei da Noite". Ele chegou ao Rio no início da década de 1930 e suas primeiras experiências na nova cidade foram em finais de 1939 em cassinos como: Urca, Quitandinha e Hotel Cassino Icaraí. Nestes estabelecimentos foi líder da famosa banda The Brazilian Serenaders. Mas foi no Cassino da Urca, a partir de 1941, que Machado e sua orquestra fizeram as apresentações mais memoráveis ao lado de nomes como Grande Otelo, a dupla de cantoras Dircinha e Linda Baptista. Neste cassino haviam duas apresentações por noite, entre as oito da noite até as três na madrugada. Para ele o bairro da Urca era um mundo à parte dentro do Rio de Janeiro (MACHADO \& PINHO, 1978, p.95-101).

No final de 1946 foi inaugurada a boate Night and Day na Cinelândia, Centro do Rio. A boate ficava na parte interna do Hotel Serrador. O local logo começou a ser frequentado por políticos, maiormente aqueles ligados ao Senado Federal e a Câmara dos Deputados devido à proximidade entre eles. O Night and Day funcionava praticamente em todos horários do dia; era um bar, restaurante para almoço, oferecia chás dançantes, restaurante para janta. No ano seguinte de sua criação, a boate passou por grande reformulação. A principal delas foi chamar Carlos Machado, recém saído do Cassino da Urca por proibição dos jogos de azar no Brasil, para ser o chefe da cozinha e também ser um dos responsáveis na preparação dos shows da casa noturna. Tornou-se em pouco tempo o diretor artístico do Night and Day necessitando contratar as atrações, as mulheres bonitas (vedetes) e imaginar cenários extasiantes e luxuosos. Como atração, contratou o pianista Waldir Calmon para liderar os chás dançantes com os crooners Alcides Gerardi e Diamantina Gomes. Na madrugada, a música ficou para Claude Austin (piano), Booker Pittman (baixo) e Louis Cole (crooner). Trio norte-americano radicado no Rio de Janeiro desde, pelo menos, 1935 - enquanto atuavam no Copacabana Palace. O repertório, a base de jazz, tocava sobretudo composições de Cole Porter e Irving Berlin (CASTRO, 2015, p.34-41). A boate fez muito sucesso, movimentando intensamente a Cinelândia. Mas devido a desentendimentos com o dono da boate, Chico Serrador, Machado 
pediu demissão da boate. Foi no Night and Day que Carlos Machado experimentou seus primeiros shows, que logo tornar-se-iam sua marca mais reconhecida.

Entretanto, logo após sair do Night and Day em 1947, Carlos Machado recebeu nova proposta para trabalhar na noite carioca: José Antônio das Neves, diretor do Banco do Comércio e Indústria, ofertou-lhe seu palacete na Gávea para Machado transformá-lo em uma boate. Das janelas dava para ver o Corcovado, o Jockey, a Lagoa Rodrigo de Freitas e Ipanema e Leblon. Machado seria o diretor-geral da casa e ainda embolsaria $10 \%$ do faturamento mensal ele aceitou de imediato o novo desafio (MACHADO \& PINHO, 1978, p.77-9). Foi no Monte Carlo que juntou música com mulheres bonitas. O show mais atrevido deste período foi chamado de "Bacanal", escrito por Silveira Sampaio. O espetáculo foi dividido em: "O Egito na Era de Cleópatra"; "Os destinos de Lucréia Bórgia e de seu pai" e "Na corte de Luiz VIII". Mas também fez sucesso a sátira musical chamada de "Um americano em Recife", estrelada por Grande Otelo (MACHADO \& PINHO, 1978, p.161). Estes seriam os modelos seguidos por Carlos Machado em produções futuras.

Em seguida que passou a administrar também a boate Casablanca, Machado mudou quase tudo. A nova decoração feita por Maria Celina Simon e o cenógrafo Armando Iglesias foi inspirada no tema musical do filme que estava em voga: "A time goes by" (intitulado "Casablanca" em português). Toda em estilo mourisco, a redecorou-a e vestiu os maîtres de smoking branco, os garçons de beduínos, os porteiros com dólmã e as vendedoras de cigarro eram odaliscas (MACHADO \& PINHO, 1978, p.162). E mais adiante menciona: "convidei Paulo Soledade e Leal Brito, o popular Britinho, para organizarem a parte artística e musical" (MACHADO \& PINHO, 1978, p.163). No jornal A Noite foi publicado a respeito desta reestruturação da boate e também sobre a contratação de Britinho pela boate Casablanca. Assim como no Perroquet, coube a Britinho formar e liderar o conjunto:

\footnotetext{
Nos dias presentes não é fácil a uma "boite" organizar um bom conjunto. Este drama experimentou o "Casablanca" agora que está sendo reedificada artisticamente. Acontece porém que a direção teve juízo e chamou um só homem e a ele entregou a incumbência de organizar um bom conjunto. Britinho, nome por demais conhecido do ambiente artístico, pelo valor de sua arte e pela disciplina de seu trabalho estará as noites alegrando as noites de "Casablanca" com o seu conjunto que ele organizou com estes elementos: Bola Sete, Laerte, K-Ximbinho, Caco Velho, Scarambone. Também Claude Bernie canta no conjunto ${ }^{15}$.
}

Ao que indica, João Leal Brito neste período já era notório entre a crítica e o público. De acordo com a matéria e o depoimento de Carlos Machado, Britinho organizou a parte

\footnotetext{
${ }^{15}$ A NOITE, Rio de Janeiro, 22 ago. 1952.
} 
musical e coube-lhe escolher os integrantes para a banda que comandaria durante as apresentações da nova boate Casablanca. Todos os músicos selecionados já eram famosos e possuíam larga experiência, pois pertenceram a outros conjuntos em outras oportunidades. $\mathrm{O}$ violonista Bola Sete, K-Ximbinho e Francisco Scarambone, chegaram a formar seus próprios grupos. Bola Sete (1923-1987) era o nome artístico do violonista e guitarrista carioca Djalma de Andrade, que tornou-se conhecido no ano de 1940 após ganhar um concurso na Rádio Transmissora para violonistas. No final dos anos de 1940 organizou Bola Sete e seu Conjunto, que teve como cantora Dolores Duran, e atuaram nas boates Vogue e Drink. Depois do Casablanca, formou nova orquestra para tocar no Hotel Glória. Com este grupo viajou para Argentina, Uruguai e Espanha (ALBIN, 2006, p.104). Sebastião de Barros (1917-1980) é o nome artístico de K-Ximbinho. Ganhou o apelido por tocar saxofone, quando foi convocado para o serviço militar. Em sua terra natal, Rio Grande do Norte, tocou principalmente em grupos de jazz. Transferiu-se para o Rio de Janeiro em 1938 quando ingressou na Orquestra Tabajara do maestro Severiano Araújo, permanecendo por quatro anos. No Rio, tornou-se conhecido como virtuoso clarinetista, compositor, arranjador e regente; dedicou-se ao jazz e choro. No início dos anos 1940 estudou harmonia e contraponto com Joachim Koellreutter. No ano de 1945 foi contratado pela boate Night and Day, em 1952 pelo Casablanca e 1955 no Sacha's (ALBIN, 2006, p.387). Mateus Nunes (1920-1971) foi um cantor, compositor e instrumentista. Gaúcho de Porto Alegre, estreou na Rádio Gaúcha no Conjunto de Piratini. Ganhou o apelido de "Caco Velho" seguidamente interpretar a canção homônima de Ary Barroso. Da década de 1940 foi para a cidade de São Paulo para atuar em boates da cidade. Algumas de suas músicas gravadas mais conhecidas foram: "Briga de gato" (Lupicínio Rodrigues), "Maria caiu do céu" (sua em parceria com Nilo Silva), "Não bobeie Calamazu (também em parceria com Nilo Silva) - quase todos seus sucessos neste período foram sambas. No auge do baião, gravou neste gênero as canções: "Abraço do baião" (de Luiz Gonzaga e David Nasser) e "A sanfona do jumento" (sua autoria em parceria com Vera Porto) (ALBIN, 2006, p.130).

O período entre maio de 1952 e dezembro de 1954, ou seja, o tempo em que João Leal Brito atuou entre as boates Perroquet e Casablanca, foram de altíssima importância para a continuidade de sua carreira enquanto músico. Britinho foi contratado pela boate Casablanca em agosto de 1952 e por lá permaneceu até o final do ano de 1954. Por esta casa noturna participou dos seguintes espetáculos: "Coisas e graças da Bahia” (entre agosto e dezembro de 1952); “Como é diferente o amor em Portugal" (entre março e maio de 1953); "Feitiço da Vila" (entre junho e agosto); "Acontece que eu sou baiano"; "Esta vida é um carnaval” (entre 
novembro e dezembro); "Satã dirige o espetáculo" (entre maio e agosto de 1954) e, por fim, "Este Rio moleque" (ente outubro e dezembro do mesmo ano).

No período em que a boate Casablanca da Praia Vermelha esteve sob arrendamento de Carlos Machado, Britinho figurou, sem dúvida, entre as grandes atrações da casa, além de organizar a orquestra da boate e participar ativamente dos ensaios. Mas não foram apenas Machado e Britinho, outros nomes como: o ator Grande Otelo, a figurinista Gisela Machado, os músicos Pernambuco e Bené Nunes, os redatores de espetáculos Fernando Lobo, Paulo Soledade e Antônio Maria - também trabalharam fortemente, na maioria dos espetáculos organizados por Machado, e com ele ajudaram a para consolidar o nome da boate Casablanca entre os principais pontos de encontro do high-society carioca.

A partir destes shows, portanto, Britinho passou a ser reconhecido líder de banda, pianista, regente, maestro e arranjador da Capital Federal. Contudo, a partir de 1951, o pianista passou a investir também na carreira fonográfica, trabalhando em centenas de discos, por diversas gravadoras.

O Rio de Janeiro, como vimos, a partir do início do século $\mathrm{XX}$, tornou-se um dos principais centros para quem almejava trabalhar dentro do circuito artístico, como por exemplo músicos e cantores, pois ali estavam as grandes emissoras de rádio do período, como: Mayrink Veiga, e, depois, Nacional e Tupi. Além disso, no Rio estavam sediadas boa parte das gravadoras, das fábricas de disco. Os músicos e cantores em meados deste século podiam empregar-se também em cassinos, boates, gafieiras, dancings, teatro de revista, bailes promovidos por clubes sociais ou esportivos (formaturas, aniversários, casamentos, debutantes), ente outras atrações.

\section{Conclusões}

Depois do espetáculo "Este Rio moleque", em dezembro de 1954, possivelmente Britinho não foi mais contratado pela boate Casablanca para atuar no Rio de Janeiro ${ }^{16}$.

No final do ano de 1954 Carlos Machado abriu uma nova boate chamada Sacha's Seven to seven, que logo tornou-se uma das principais boates de Copacabana - conhecido como o templo da alta sociedade, superando, inclusive, o Vogue, do Barão de Stuckart. Machado conseguiu contratar do Vogue o pianista austríaco Salomon Rubin. Ele era conhecido em cidades espalhadas pelo mundo, como: Viena, Zurique, Lausanne, Carlsbad,

\footnotetext{
${ }^{16}$ Sabemos que dois anos depois, em 07 de dezembro de 1956, Carlos Machado, Grande Otelo, Gisela Machado, Britinho e parte do elenco do Casablanca foram convidados para uma apresentação em Nova York, Estados Unidos (THORMES, Jacinto. Diário da Noite, Rio de Janeiro, 07 dez. 1956).
} 
Baden Baden, Chamonix, Saint Moritz, Budapeste, Cairo, Alexandria, Beirute, Damasco, Bagdá, Istambul, Ancara e Londres. Da capital britânica, migrou para o Rio de Janeiro, onde anos mais tarde naturalizou-se brasileiro. Em todas as cidades que tocou piano, ele foi conhecido simplesmente por Sacha (MACHADO \& PINHO, 1978, p.173-5). Assim que Carlos Machado soube, através de Lúcio Schiller, que Sacha procurava um parceiro para abrir uma boate sua, Machado fez uma proposta ao pianista austríaco - que logo a aceitou. Machado entraria com o capital inicial; e Sacha, além de ser a estrela principal da casa, daria seu nome a nova boate.

Entretanto, em seguida depois de abrir o Sacha’s, porém já em 1955, Carlos Machado teve o pedido negado pela Prefeitura do Rio de Janeiro para prosseguir o arrendamento do prédio onde localizava-se Casablanca, na Praia Vermelha, aos pés da Urca. Carlos Machado inicialmente se deparou com a boate Casablanca em más condições, mas após grande reforma, fez dela um ponto de referência em toda a cidade. O ponto tornou-se altamente valorizado, e com isso, não houve negociação com a prefeitura capaz reverter a situação. Com isso o Casablanca foi fechado ${ }^{17}$. A partir de 1954 Carlos Machado passou a administrar as boates Beguin (situada no Hotel Glória), Arpège e Night and Day.

Após Carlos Machado inaugurar o Sacha's em 1954, o colunista e redator de shows da madrugada, Paulo Soledade, escreveu uma coluna com título: "Porque não Britinho?”:

\begin{abstract}
Quando o "Casablanca" abriu, levou para lá o pianista Britinho, que conhecemos através das gravações com Fat's Elpídio na RCA Victor. Com o nome de Leal Brito o maestro iniciou a escrever, orquestrar e ensaiar os espetáculos daquela casa. Passaram-se dois anos, nos quais ele vem sendo o esteio da parte musical daqueles espetáculos. Além do mais, bom solista, Britinho defendeu com seu talento vários artistas que se apresentaram nos "shows" e, com sua dedicação, permitiu a rotina de trabalho que o obrigava a tocar até altas horas da noite aproveitando os intervalos das folgas dos espetáculos. No dia seguinte era o primeiro a chegar, sendo que às vezes ao meio-dia, para ensaiar separado determinados quadros, e contava não haver dormido quase a fim de entregar o seu trabalho pronto na hora necessária. Tornou-se assim imprescindível. Agora que as coisas melhoraram e que parece está sobrando dinheiro, Carlos Machado resolveu abrir um novo bar e para tal contratou o bom pianista que era do "Vogue" Sacha. Não sabemos porque não foi Britinho o contemplado com a sociedade que Machado ofereceu no seu novo bar, que além da participação do lucro dá a Sacha um grande prestígio pois chamar-se-á Sacha's Bar. Valerá a pena Britinho vir se empenhando dessa maneira para quem não reconhece o seu esforço? E não será ele tão bom pianista quanto o outro? ${ }^{18}$
\end{abstract}

Não sabemos os motivos de Carlos Machado ter escolhido Sacha Rubin para a sociedade na nova boate. Contudo, em finais de 1954, Britinho dedicava-se firmemente a

\footnotetext{
17 Depois de fechar na década de 1950 o prédio tornou-se uma escola. Atualmente, é onde localiza-se a embaixada da Itália na cidade do Rio de Janeiro.

${ }^{18}$ SOLEDADE, Paulo. Revista da Semana, Rio de Janeiro, 1954.
} 
carreira fonográfica, o que pode ter diminuído o tempo para dedicar-se aos espetáculos do Casablanca. Entre 1951 e 1954 Britinho lançou pelo menos dez discos (7 deles pela gravadora Musicdisc; Todamérica, Copacabana e RCA Victor, um disco apenas por cada uma delas); e além disso, havia uma curta carreira fonográfica de sucesso ao lado do também pianista da noite Fat's Elpídio. Sobre a provável "pausa” de Britinho, saiu publicado no Diário da Noite: “Britinho (ao piano), com Fat's Elpídio. Dois estilos, dois excelentes pianistas. "Fat's Elpídio faz mais feliz as noites do Copacabana Palace. E Britinho? Por onde anda?" "19. Considerando somente o ano de 1955, João Leal Brito lançou 13 discos.

Em uma de suas célebres colunas sobre a boemia carioca - Dicionário enciclopédico da noite - o carioca Stanislaw Ponte Preta escreveu sobre João Leal Brito:

\begin{abstract}
Britinho - Músico. O nome verdadeiro de Britinho lembra doce em calda, parece fábrica de conserva: chama-se Leal Brito. Pianista de dotes festejados, Britinho é também orquestrador, inclusive de "shows" ("Feitiço da Vila", "Acontece que eu sou baiano", etc). Já tocou em dezenas de lugares mas, no momento, dedica-se apenas a gravações. Alguns dos seus discos mais interessantes foram gravados em duo de piano com "Fat's Elpídio" cujo, como ele, é um velho pianista da noite carioca $^{20}$.
\end{abstract}

Após sair da boate Casablanca em 1954 João Leal Brito passou a viver quase que exclusivamente dos diretos autorais oriundos de sua carreia fonográfica; além disto, também passou a tocar juntamente com sua orquestra em diversas festas, bailes e formaturas do highsociety carioca.

Britinho possui uma extensa discografia, lançada entre os anos de 1951-1966. Em nosso levantamento sobre sua obra possuímos 120 discos listados e divididos nas seguintes categorias: 66 discos de carreira, 41 discos em participações e 13 discos como integrante de grupos. A partir dos discos de carreira possuímos um total de 77 músicas de sua autoria ou em parcerias: 26 músicas de sua autoria; 29 em parceria com Fernando César; 4 em parceria com o pianista Fat's Elpídio e 18 em parceria com diversos compositores.

O pianista/ maestro Leal Brito também tornou-se popularmente conhecido em finais dos anos de 1950 por lançar discos utilizando pseudônimos. O mais conhecido entre eles é o codinome de "Pierre Kolmann", nos discos lançados pela gravadora Musicdisc a partir de 1957, com a série "Para Dançar" (em quatro volumes), entre outros discos de "Kolmann". Entre os pseudônimos utilizados por ele nas gravações, além de Pierre Kolmann estão: Franca Villa, 58 (Sinter); Al Brito, 58 (Columbia); Tito Romero, 59 (Polydor); Miriam Presley, 59

\footnotetext{
${ }^{19}$ DIÁRIO da Noite, Rio de Janeiro, 15 jan. 1955.

${ }^{20}$ ÚLTIMA Hora, Rio de Janeiro, 21 maio 1956.
} 
(Discos Drink); Al Person, 62 (Sideral); Al Newman, 62 (Som/ Copacabana); Milton-Z e Jone Braith.

Além de estudar o músico dentro do contexto das boates, da Zona Sul do Rio de Janeiro, é preciso, portanto, esmiuçar a extensa discografia de Britinho. Entre as questões norteadoras podemos considerar: A quais gêneros Britinho dedicou-se? Quais foram suas composições mais conhecidas entre o público? Quais cantores ou músicos gravaram suas músicas? Por fim procuraremos problematizar o porquê de Britinho utilizar diversos pseudônimos em suas gravações. O que estava aí envolvido? A possibilidade de gravar diversos gêneros? A possibilidade de fazer versões de músicas estrangeiras? Quebra de contrato com as gravadoras?

\section{Referências}

ALBIN, R. C. Dicionário Houaiss Ilustrado: Música Popular Brasileira. Rio de Janeiro: Paracatu, 2006. (Obra completa)

BOURDIEU, P. A ilusão biográfica. In: FERREIRA, Marieta; AMADO, Janaína. (Orgs.). Usos e abusos da História Oral. 8 ed. Rio de Janeiro: Editora FGV, 2006. pp. 183-92. (Capítulo de livro)

CABRAL, S. MPB na Era do rádio. São Paulo: Lazuli, 2011. (Obra completa)

CARDOSO, S. T. Dicionário Biográfico de Música Popular. Rio de Janeiro: Edição do Autor, 1965. (Obra completa)

CARDOSO, S. O. \& MACHADO, H. L.. "A Galeria do Amor" - cidade, corpo e emoções na música de Agnaldo Timóteo. In: XXXVIII Congresso Brasileiro de Ciências da Comunicação, Rio de Janeiro. Anais. João Pessoa, 2015. (Trabalho em Anais de Congresso)

CASTRO, R. Chega de saudade: a história e as histórias da Bossa Nova. São Paulo:

Companhia das Letras, 1990. (Obra completa)

. A noite do meu bem: a história e as histórias do samba-canção. São Pauo: Companhia das Letras, 2015. (Obra completa)

CONTIER, A. D. Música no Brasil: História e Interdisciplinaridade. Algumas interpretações (1926-80). In: Anais do XVI Simpósio da Associação Nacional dos Professores de Histórial ANPUH/ História em Debate: problemas temas e perspectivas. Rio de Janeiro, 22 a 26 de junho de 1991. (Trabalho em Anais de Congresso)

DOSSE, F. O desafio biográfico: escrever uma vida. São Paulo: Editora da USP, 2009. (Obra Completa)

ESTEPHAN, S. Aníbal Augusto Sardinha, o Garoto (1915-1955) e a Era do Rádio no Brasil. Projeto História, São Paulo, n. 43, pp. 161-83, dez. 2011. 
LENHARO, A. Cantores do rádio: a trajetória de Nora Ney e Jorge Goulart e o meio artístico de seu tempo. Campinas: Editora da Unicamp, 1995. (Obra completa)

LEVI, G. A herança imaterial: trajetória de um exorcista no Piemonte do século XVII. Rio de Janeiro: Civilização Brasileira, 2000. (Obra Completa)

. Usos da biografia. In: FERREIRA, Marieta; AMADO, Janaína. (Orgs.). Usos e abusos da História Oral. 8 ed. Rio de Janeiro: Editora FGV, 2006. pp. 167-82.

LOPES, M. A. Foi assim: contribuição para um estudo histórico do samba-canção (19461957). 2011. 109 p. Dissertação (Mestrado em História Social), Faculdade de Filosofia e Ciências Humanas, Universidade Federal da Bahia, Salvador, 2011. (Dissertação)

MACHADO, C. \& PINHO, F. Memórias sem maquiagem. São Paulo: Cultura, 1978. (Obra completa)

MATOS, M. I. Dolores Duran: experiências boêmias em Copacabana nos anos 50. 2 ed. Rio de Janeiro: Bertrand Brasil, 2005. (Obra completa)

MÁXIMO, J. \& DIDIER, C. Noel Rosa: uma biografia. Brasília: Editora Universidade de Brasília, 1990. (Obra completa)

MELLO, Z. H. de. \& SEVERIANO, J. A canção no tempo: 85 anos de músicas brasileiras. São Paulo: Editora 34, 1997. (2 vols.). (Obra completa)

MESQUITA, C. De Copacabana à Boca do Mato: o Rio de Janeiro de Sérgio Porto e Stanislaw Ponte Preta. Rio de Janeiro: Edições Casa de Rui Barbosa, 2008. (Obra completa)

MORAES, J. G. V.; SALIBA, E. T. (Orgs.). História e música no Brasil. São Paulo: Alameda, 2010. (Capítulo de livro)

NAPOLITANO, M. História \& Música: história cultural da música popular. 3 ed. Belo Horizonte: Autêntica, 2005. (Obra completa)

OLIVEIRA, M. R. Lupicínio Rodrigues: a cidade, a música, os amigos. 1995. 262 p.

Dissertação (Mestrado em História), Instituto de Filosofia e Ciências Humanas, Universidade Federal do Rio Grande do Sul. Porto Alegre, 1995. (Dissertação)

. Uma leitura histórica da produção do compositor Lupicínio Rodrigues. 2002. 302 p. Tese (Doutorado em História), Instituto de Filosofia e Ciências Humanas, Universidade Federal do Rio Grande do Sul, Porto Alegre, 2002. (Tese)

SANTOS, J. F. dos. Antônio Maria: noites de Copacabana. 2 ed. Rio de Janeiro: Relume Dumará, 1996. (Obra completa)

SCHMIDT, B. Em busca da terra da promissão: a história de dois líderes socialistas. Porto Alegre: Palmarinca, 2004. (Obra completa) 
SANTOS, V. S. M. Minha alma canta, vejo o Rio de Janeiro: a Zona Sul carioca entre crônicas e canções. 2013. 270 p. Tese (Doutorado em História, Política e Bens Culturais), Centro de Pesquisa e Documentação de História Contemporânea do Brasil, Fundação Getúlio Vargas. Rio de Janeiro, 2013. (Tese) 